\title{
ADSORPTION OF CIPROFLOXACIN FROM AQUEOUS ENVIRONMENT BY USING SYNTHESIZED NANOCERIA
}

\author{
ADSORPCJA CIPROFLOKSACYNY ZE ŚRODOWISKA WODNEGO \\ ZA POMOCĄ ZSYNTEZOWANYCH NANOCZĄSTEK TLENKU CERU
}

\begin{abstract}
Antibiotics are widely detected emerging contaminants in water environments and possess high potential risks to human health and aquatic life. However, conventional water treatment processes cannot remove them sufficiently. To develop innovative nanoadsorbents for effectively remove antibiotic contaminants from water environment, nanoceria were prepared via in situ precipitation method, and evaluated their adsorption capacity for a model antibiotic, ciprofloxacin (CIP). The properties of the prepared nanoceria were characterized by transmission electron microscopy (TEM), X-ray diffraction (XRD) and vibration sample magnetization (VSM). The effect of various operating parameters such as $\mathrm{pH}$, initial CIP concentration, contact time, and adsorbent dosage on adsorptions of CIP were studied in batch experiments. Maximum adsorption capacity of the nanoceria was $49.38 \mathrm{mg} / \mathrm{g}$ at the conditions of $\mathrm{pH} 5$, initial CIP concentration of $200 \mathrm{mg} / \mathrm{dm}^{3}$ and adsorbent dosage of $0.2 \mathrm{~g} / \mathrm{dm}^{3}$, when $95.43 \%$ of the CIP was removed. For adsorption kinetics, both pseudo-first-order and pseudo-second-order models can well describe the experimental data, indicating that the adsorption process was controlled by both physical diffusion and chemical interaction. For adsorption isotherms, the Freundlich model could fit the experimental data better than the Langmuir and Temkin models, suggesting a multilayer adsorption process. The thermal dynamics study showed the absorption process was spontaneity, exothermic, and irreversible. Finally it was concluded that the nanoceria can be used effectively for CIP removal.
\end{abstract}

Keywords: ciprofloxacin, cerium oxide nanoparticles, adsorption of ciprofloxacin, isotherm model, antibiotic pollutants, thermodynamics studies

\section{Introduction}

Today, the drugs in the environment have been considered as emerging contaminants and have attracted more and more attentions. They were used in treatments of infections and curing the microbial, viral, fungal and parasites agents for 70 years [1]. Antibiotics are a big branch of pharmaceutical substances, which consisted of $15 \%$ of total drugs consumptions [2]. Annual application of antibiotics is 100,000 to 200,000 Mg per year [3]. Antibiotics are in human body in very low concentration and large parts of them are excreted by urine and feces. In addition, the wastewater produced by pharmaceutical

\footnotetext{
${ }^{1}$ Department of Physics, University of Zabol, Zabol, P. O. Box. 98613-35856, Iran

${ }^{2}$ Department of Environmental Health, Zabol University of Medical Sciences, Zabol, Iran

${ }^{3}$ Department of Environmental Science \& Engineering, Fudan University, Shanghai 200438, China

*Corresponding Authors: rahdar89@gmail.com, jiefu@fudan.edu.cn, phone and fax +86-21-31248907
} 
industry contain large amounts of antibiotics, and the inappropriate treatment of such wastewater will result in serious water pollution [4]. Different concentrations $\left(1-100 \mu \mathrm{g} / \mathrm{dm}^{3}\right)$ of antibiotics were observed in underground water, surface water and lakes. Significant amount of antibiotics were even found in liver of trout and brain of shrimps [5]. Their presence resulted in bacterial drug resistance in low concentration, and threat the human healthy [6]. In addition to their chemical pollution, they showed high stability and diffusion ability [7]. Therefore, antibiotics have been the most concerned by the scientific community and the public in recent years. Ciprofloxacin (CIP) is a typical synthetic antibiotic, which belongs to fluoroquinolones, and it is used to treat the urinary tract infections, certain type of infectious diarrhea, and respiratory tract infections. The fluorine atom in structure of CIP resulted in high stability of this antibiotic [8]. It is shown that more than $95 \%$ of CIP would not be decomposed during the uptaking and it found its way to sewage [9].

The antibiotics show the lower biodegradability, high toxicity, carcinogenicity and mutagenicity, and they increase the allergic reactions and induce the population increase of antibiotic resistance bacteria in human and animals [10,11]. Different methods have been developed to treat antibiotic pollutants including coagulation, reverse osmosis, absorption on active carbon, ozonation, advanced oxidation systems like Fenton or photo-Fenton, ultrasonic degradation, pre-oxidation with UV lamp, and biofiltration [12, 13]. However, coagulation and centrifuge made a secondary pollutant, and biological methods were timeconsuming and had low efficiency [14]. The antibiotic presence in wastewater prevents bacterial activity [15]. In addition, they cause toxicity in microorganisms that are used in filtration and produce high biomass [10]. Advanced oxidation process needs high energy and it was not often used because of economic limitation.

Surface adsorption is the most effective method in purification of sewage as it provides the advantages of simple design, easy to manage, high efficiency, less sludge production and environment friendly $[16,17]$. The boom in nanoscience and nanotechnology offers opportunities to develop innovative techniques in removing the pollutants from aqueous solutions using iron, titanium, manganese and cerium oxides nanoparticles. Nanoparticles can provide high special surface for chemical reactions and absorption of organic compounds. Cerium oxide nanoparticles $\left(\mathrm{CeO}_{2}-\mathrm{NPs}\right)$ are effective nanoadsorbents because of high special surface, physical and chemical properties and electrical charges, and have been investigated for adsorbing various pollutants including heavy metals [18], dyes [19], and nutrients [20]. Yet, the adsorption information of $\mathrm{CeO}_{2}-\mathrm{NPs}$ for antibiotics are limited. To this end, $\mathrm{CeO}_{2}$-NPs were synthesized and evaluated their adsorption capacity for the model antibiotic CIP from aqueous environment. Adsorption kinetics, equilibrium isotherm and thermodynamics have been systematically studied. The operating parameters such as initial $\mathrm{pH}$ of solution, adsorbent dosage, initial pollutant concentration and contact time on the adsorption capacity of $\mathrm{CeO}_{2}$-NPs for CIP removal have also been investigated and optimized.

\section{Materials and methods}

\section{Chemicals and reagents}

Ciprofloxacin (molecular weight $367.8 \mathrm{~g} / \mathrm{mol}$, purity higher than $99.6 \%$, molecular formula $\mathrm{C}_{17} \mathrm{H}_{18} \mathrm{FN}_{3} \mathrm{O}_{3}$, and acidity coefficient $\mathrm{p} K_{\mathrm{a}}=5.7$ ) was supplied by Sigma-Aldrich, USA. Stock of CIP with concentration of $1.000 \mathrm{mg} / \mathrm{dm}^{3}$ was prepared in double distilled 
water. The chemical structure CIP is provided in Figure 1. Sodium hydroxide $(\mathrm{NaOH}$, $98 \%)$ and hydrochloric acid $(\mathrm{HCl}, 37 \%)$ used in the study were of analytical grade and were supplied by Sigma-Aldrich.

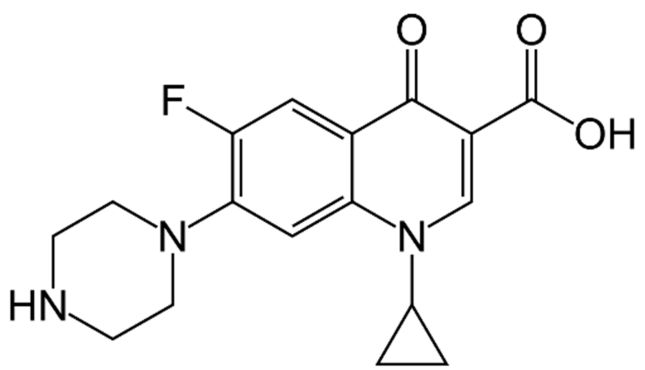

Fig. 1. Chemical structure of ciprofloxacin

\section{Preparation and characterization of nanoadsorbent}

To prepare of $\mathrm{CeO}_{2}$-NPs, $11.235 \mathrm{~g}$ of cerium nitrate $\left(\mathrm{Ce}\left(\mathrm{NO}_{3}\right)_{3} \cdot 6 \mathrm{H}_{2} \mathrm{O}\right)$ was dissolved in $50 \mathrm{~cm}^{3}$ of distilled water and then stirred for $20 \mathrm{~min}$. Meanwhile, $0.0323 \mathrm{~g}$ of xanthan gum was dissolved in $60 \mathrm{~cm}^{3}$ of distilled water and stirred for $20 \mathrm{~min}$ to achieve a clear xanthan gum solution. Afterwards, the cerium nitrate solution was added to the xanthan gum solution, and stirred for $40 \mathrm{~min}$. In this solution a $3 \mathrm{M}$ ammonia solution was slowly added under stirring until the $\mathrm{pH}$ value 9 is reached. The particle was collected by centrifugation at $5000 \mathrm{rpm}$ for ten minutes. The centrifuged particles were washed with water and again subjected to centrifugation at $5000 \mathrm{rpm}$ for $4 \mathrm{~min}$. The centrifuged sample, dried for $24 \mathrm{~h}$ at room temperature, was powdered using mortar and pestle.

The microstructure analysis of $\mathrm{CeO}_{2}$-NPs was performed using transmission electron microscopy (TEM) (Philips CM-12 Model). The X-ray diffraction (XRD) pattern of $\mathrm{CeO}_{2}$-NPs was obtained on a D8 powder X-ray diffractometer with $\mathrm{Cu} \mathrm{K \alpha}$ radiation (Bruker, Billerica, MA, USA). The magnetic property of $\mathrm{CeO}_{2}-\mathrm{NPs}_{\text {sas }}$ confirmed by vibration sample magnetization (VSM) tool.

\section{Antibiotic adsorption experiments}

In order to remove CIP, the adsorption experiment by $\mathrm{CeO}_{2}-\mathrm{NPs}$ was conducted in a $250 \mathrm{~cm}^{3}$ Erlenmeyer on a shaker. A $50 \mathrm{~cm}^{3}$ of CIP stock with different concentrations $\left(20-100 \mathrm{mg} / \mathrm{dm}^{3}\right)$ and $\mathrm{pH}$ values (3-11) were prepared using distilled water. The $\mathrm{pH}$ were adjusted with $\mathrm{HCl}$ and $\mathrm{NaOH}$. $\mathrm{CeO}_{2}-\mathrm{NPs}$ were added to solution and the mixture was shaking on a shaker. The samples were taken at set time intervals, filtered using Whatman filter paper $(0.45 \mu \mathrm{m})$, and then subjected to CIP measurement on a spectrophotometer (CE-1021, Shimadzu, Tokyo, China) at the absorbance of $276 \mathrm{~nm}$. The adsorption capacity of $\mathrm{CIP}$ on $\mathrm{CeO}_{2}-\mathrm{NPs}\left(q_{e}[\mathrm{mg} / \mathrm{g}]\right)$ and removal effeciency $(\operatorname{Re}[\%])$ were calculated using the following equations [21]:

$$
q_{e}=\frac{\left(C_{o}-C_{e}\right) V}{M}
$$




$$
R e=\frac{\left(C_{o}-C_{e}\right)}{C_{o}} \cdot 100 \%
$$

where $C_{0}$ and $C_{e}$ were initial and equibilirum concentration of CIP in aqueous phase $\left[\mathrm{mg} / \mathrm{dm}^{3}\right], V$ was solution volume $\left[\mathrm{dm}^{3}\right]$ and $M$ was the mass of $\mathrm{CeO}_{2}-\mathrm{NPs}[\mathrm{g}]$. Each experiment was replicated twice, and the mean values were reported.

\section{Results and discussion}

\section{Characterization of $\mathrm{CeO}_{2}$-NPs}

Figure 2 presents the TEM image of $\mathrm{CeO}_{2}$-NPs. The range of diameters of $\mathrm{CeO}_{2}-\mathrm{NPs}$ are about 40-90 nm. Figure 3 shows the XRD spectrum of $\mathrm{CeO}_{2}-\mathrm{NPs}$. The XRD peaks located at angles $(2 \theta)$ of $28.57^{\circ}, 33.09^{\circ}$ and $47.48^{\circ}$ are corresponding to (111), (200) and (220) planes of the $\mathrm{CeO}_{2}$-NPs. Other peaks found at $2 \theta$ of $56.35^{\circ}, 59.12^{\circ}, 69.37^{\circ}, 76.67^{\circ}$ and $79.11^{\circ}$ are corresponding to (311), (222), (400), (331) and (420) planes of $\mathrm{CeO}_{2}-\mathrm{NPs}$ that can be indexed as the fluorite cubic structure (JCPDS \#00-034-0394). The average crystallite size $(D)$ of $\mathrm{CeO}_{2}$-NPs was calculated by the Scherer formula:

$$
D=\frac{K \lambda}{\beta \cos \theta}
$$

where $K$ is a dimensionless shape factor and has a typical value of about $0.9, \lambda$ is the wavelength of $\mathrm{Cu} K \alpha(1.542 \AA), \beta$ is the full width at half maximum (FWHM) of the line, and $\theta$ is the diffraction angle using (311) plane reflection from the XRD pattern. The calculated crystallite size of $\mathrm{CeO}_{2}-\mathrm{NPs}$ is $34.21 \mathrm{~nm}$ with a lattice parameter of 5.4204. In addition, the VSM curve (Fig. 4) confirms the magnetic properties of $\mathrm{CeO}_{2}-\mathrm{NPs}$, which is in agreement with the reported results in literature [22].

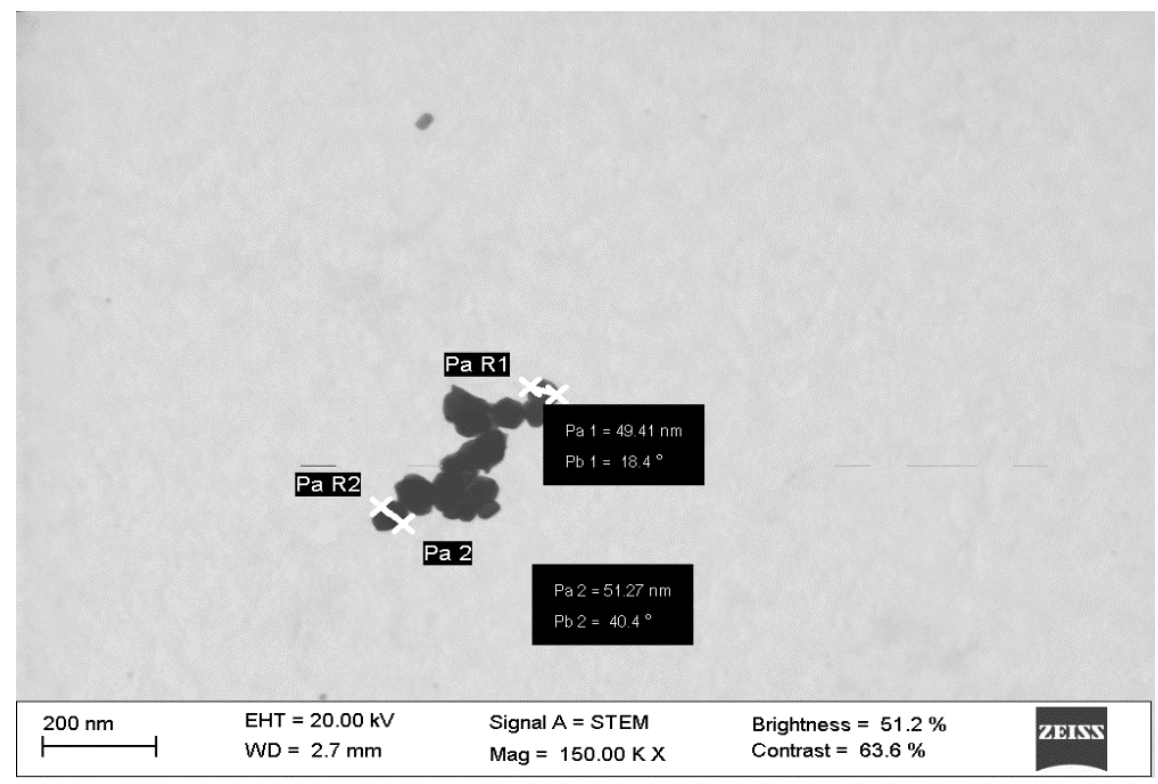

Fig. 2. TEM image of cerium oxide nanoparticles 


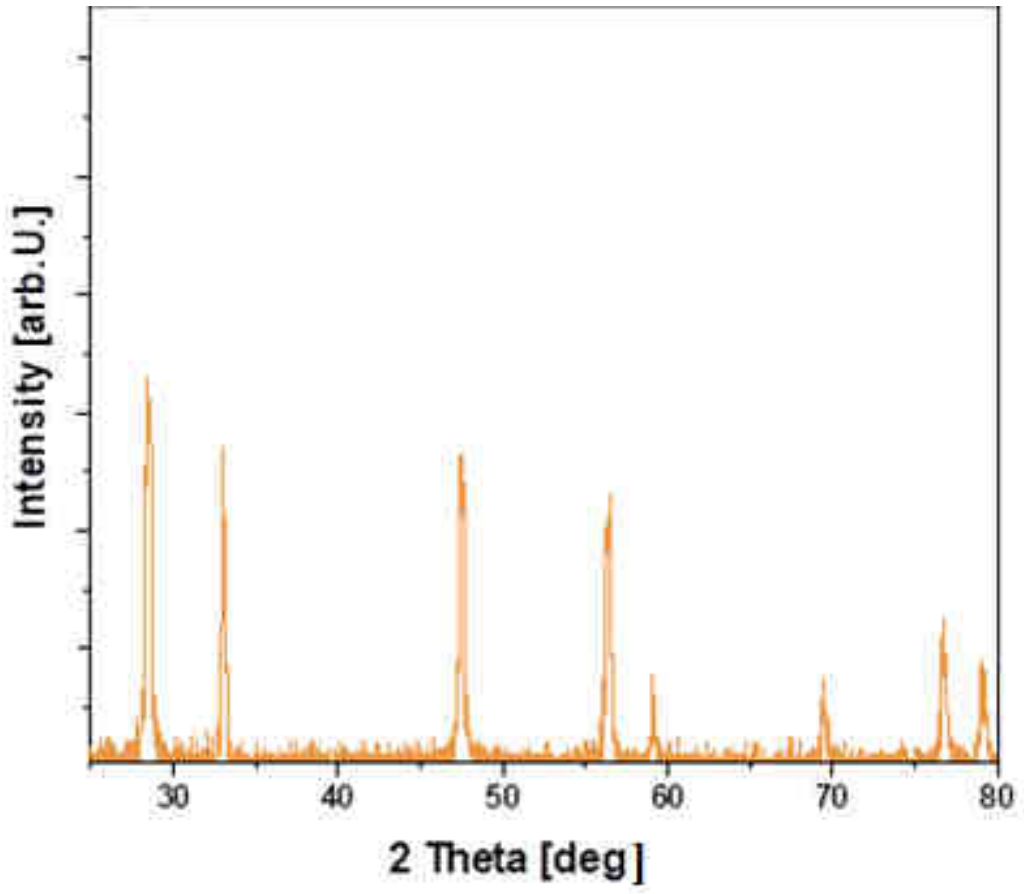

Fig. 3. XRD spectrum of cerium oxide nanoparticles

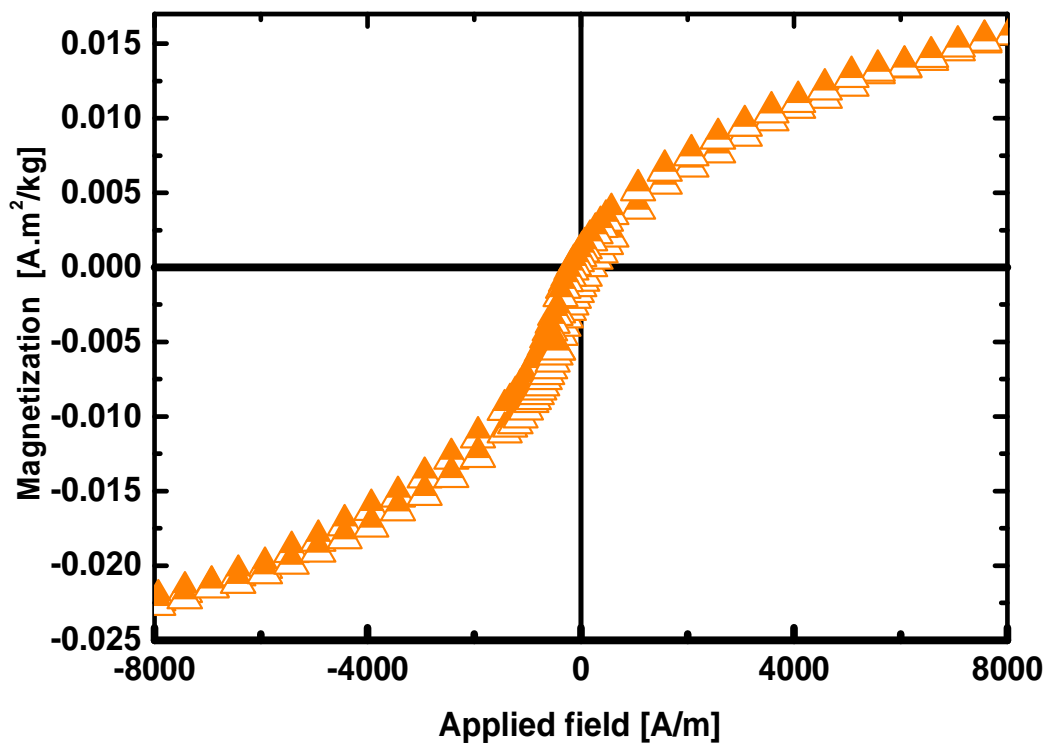

Fig. 4. M-H loops of cerium oxide nanoparticles 


\section{Adsorption kinetics}

Adsorption of CIP onto $\mathrm{CeO}_{2}$-NPs over time is displayed in Figure 5. It is observed that $\mathrm{CeO}_{2}$-NPs could quickly capture CIP from aqueous solution. The adsorption mainly occurred in the first $20 \mathrm{~min}$ and could rapidly reach equilibrium within $80 \mathrm{~min}$ for an varying initial CIP concentration from 20 to $200 \mathrm{mg} / \mathrm{dm}^{3}$. The equilibrium adsorption capacity was ranged from 4.78 to $49.85 \mathrm{mg} / \mathrm{g}$. Pseudo-first-order and pseudo-second-order models are used to analyze the kinetics results, which are expressed as [23]:

$$
\begin{array}{lc}
\text { pseudo-first-order models: } & \ln \left(q_{e}-q_{t}\right)=\ln q_{e}-k_{1} t \\
\text { pseudo-second-order model: } & \frac{t}{q_{t}}=\frac{1}{k_{2} q_{e}^{2}}+\frac{t}{q_{e}}
\end{array}
$$

where $q_{t}$ and $q_{e}[\mathrm{mg} / \mathrm{g}]$ are the adsorption capacities of CIP at time $t$ [min] and equilibrium, respectively. $k_{1}\left[\mathrm{~min}^{-1}\right]$ and $k_{2}[\mathrm{~g} / \mathrm{mg} \cdot \mathrm{min}]$ are the rate constants of the pseudo-first-order and pseudo-second-order kinetic models, respectively. Table 1 lists the parameters for the two kinetic models. Obviously, both models can well describe the adsorption kinetic results, indicating that the adsorption of CIP onto $\mathrm{CeO}_{2}-\mathrm{NPs}$ was controlled by both physical diffusion and chemical interaction.

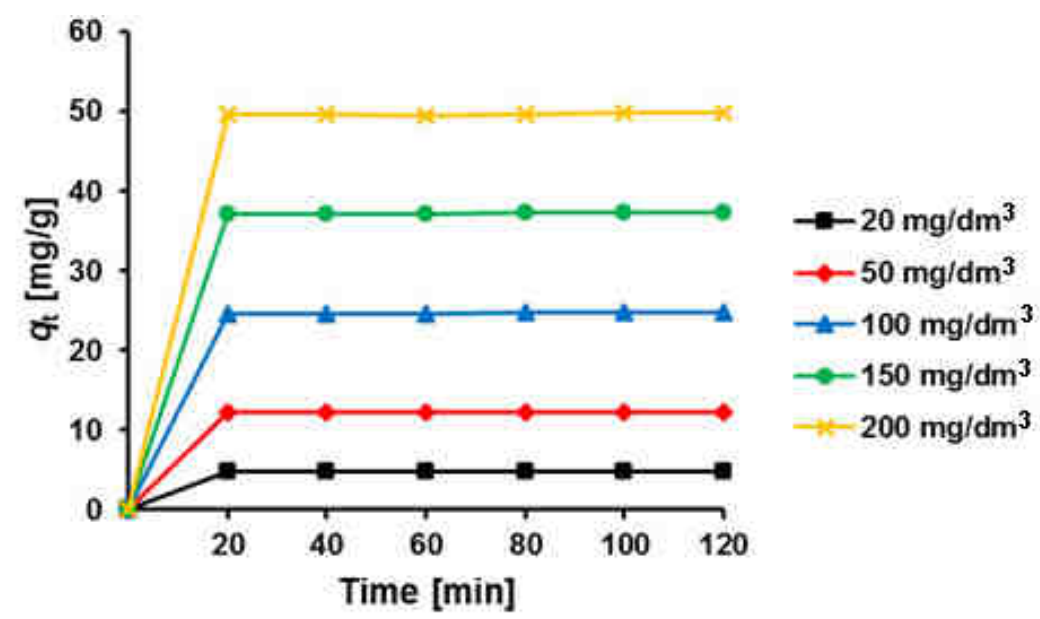

Fig. 5. Adsorption kinetics of ciprofloxacin onto cerium oxide nanoparticles. Experimental conditions: $\mathrm{CeO}_{2}-\mathrm{NPs}$ dosage $0.2 \mathrm{~g} / \mathrm{dm}^{3}$, initial CIP concentration $20-200 \mathrm{mg} / \mathrm{dm}^{3}, \mathrm{pH}=5$

Table 1

Kinetic parameters for adsorption of ciprofloxacin by cerium oxide nanoparticles

\begin{tabular}{|c|c|c|c|c|c|c|}
\hline \multirow{2}{*}{ Kinetic model } & \multirow{2}{*}{ Parameters } & \multicolumn{5}{|c|}{ Initial CIP concentration [mg/dm $\mathbf{m}^{\mathbf{3}}$} \\
\cline { 2 - 7 } & & $\mathbf{2 0}$ & $\mathbf{5 0}$ & $\mathbf{1 0 0}$ & $\mathbf{1 5 0}$ & $\mathbf{2 0 0}$ \\
\hline \multirow{2}{*}{$\begin{array}{c}\text { Pseudo-first-order } \\
\text { model }\end{array}$} & $q_{e}[\mathrm{mg} / \mathrm{g}]$ & 4.78 & 12.25 & 24.72 & 37.21 & 49.72 \\
\cline { 2 - 7 } & $k_{1}\left[\mathrm{~min}^{-1}\right]$ & 0.342 & 0.259 & 0.322 & 0.326 & 0.315 \\
\cline { 2 - 7 } & $R^{2}$ & 0.9999 & 0.9999 & 0.9999 & 0.9999 & 0.9999 \\
\hline \multirow{2}{*}{$\begin{array}{c}\text { Pseudo-first-order } \\
\text { model }\end{array}$} & $q_{e}[\mathrm{mg} / \mathrm{g}]$ & 4.80 & 12.30 & 24.84 & 37.40 & 49.98 \\
\cline { 2 - 7 } & $k_{2}[\mathrm{~g} /(\mathrm{mg} \cdot \mathrm{min})]$ & 0.965 & 0.309 & 0.139 & 0.089 & 0.067 \\
\cline { 2 - 7 } & $R^{2}$ & 0.9999 & 1.0000 & 1.0000 & 1.0000 & 1.000 \\
\hline
\end{tabular}




\section{Adsorption isotherms}

Isotherms usually showed the relation between adsorbed antibiotic mass per gram of absorbent and residual antibiotic concentration in solution in equilibrium condition. Figure 6 presents the adsorption isotherm results. The adsorption equilibrium models were used to show the adsorption equilibrium and measurement of the adsorption rate in different conditions. These models showed how absorbed molecules in solid and liquid phases will distribute in equilibrium condition, so they provided comprehensive and complete view about mechanism, surface properties and absorbing condition [24, 25]. The most important adsorption isotherm models were Langmuir model, Freundlich model, and Temkin model.

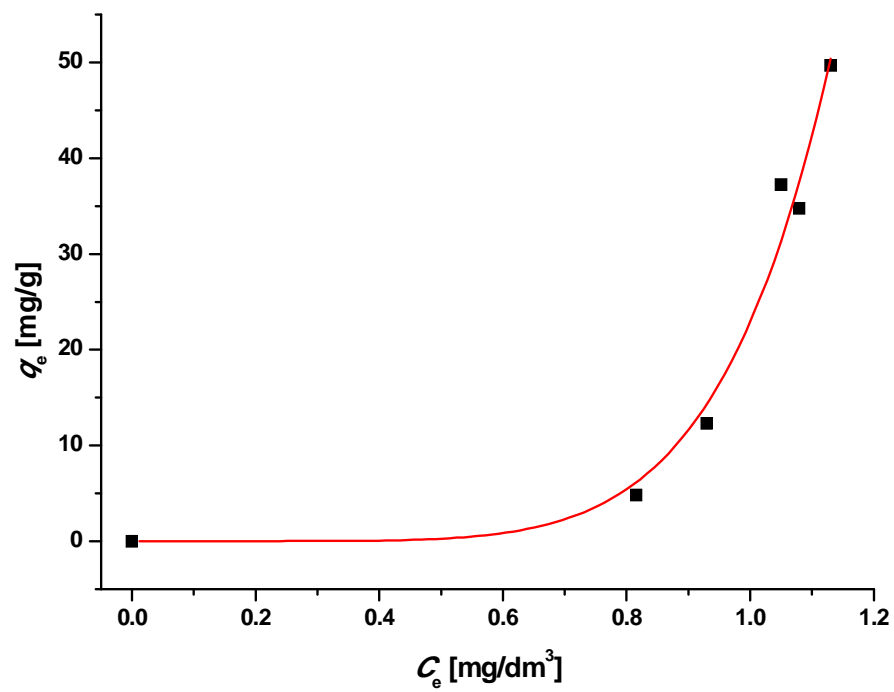

Fig. 6. Adsorption isotherm of ciprofloxacin onto cerium oxide nanoparticles with Freundlich model fitting. Experimental conditions: $\mathrm{CeO}_{2}-\mathrm{NPs}$ dosage $0.2 \mathrm{~g} / \mathrm{dm}^{3}$, initial CIP concentration $20-100 \mathrm{mg} / \mathrm{dm}^{3}, \mathrm{pH}=5$

The Langmuir isotherm model was based on solid scientific assumptions. It is assumed that adsorbates (atoms, molecules or ions) will bind to determined and uniform sites on absorbents surface and the monolayer absorption process will happened. The model can be expressed as below [21]:

$$
q_{e}=\frac{q_{m} K_{L} C_{e}}{1+K_{L} C_{e}}
$$

where $q_{e}$ and $C_{e}$ are adsorption capacity $[\mathrm{mg} / \mathrm{g}]$ and concentration of adsorbates at equilibrium, $K_{L}$ is Langmuir constants, and $q_{m}$ is the maximum adsorption capacity [mg/g]. The Langmuir equation could be calculated in linear condition using $q_{m}$ and $K_{L}$ with drawing the curve $1 / q_{e}$ versus $1 / C_{e}[23]$ :

$$
\frac{1}{q_{e}}=\frac{1}{q_{m}}+\frac{1}{q_{m} K_{L}} \frac{1}{C}
$$


The Freundlich isotherm assumes an exponentially decaying sorption site energy distribution. This is an experimental model and is applicable to non-ideal sorption on heterogeneous surfaces as well as multi-layer sorption and is expressed by the following equation [25]:

$$
q_{e}=K_{F} C_{e}^{\frac{1}{n}}
$$

where $K_{F}$ and $1 / n$ are the Freundlich constants that are related to the adsorption capacity and the adsorption intensity, respectively. The Freundlich constants can be obtained by drawing the $\log q_{e}$ versus $\log C_{e}$ based on experimental data in light to linear equation [23]:

$$
\log q_{e}=\log K_{F}+\frac{1}{n} \log C_{e}
$$

In order to validate the adsorption isotherm model used in the study, in addition to coefficient of determination $R^{2}$, the parameters of Marquardt's percent standard deviation $(M P S D)$, Hybrid error function $(H Y B R I D)$, and relative error $\Delta q_{e}[\%]$ were also evaluated, which can be described as follows [26]:

$$
\begin{gathered}
M P S D=100 \sqrt{\frac{1}{n-p} \sum_{i=1}^{n}\left(\frac{q_{e, \exp }-q_{e, \mathrm{cal}}}{q_{e, \exp }}\right)_{i}^{2}} \\
H Y B R I D=\frac{100}{n-p} \sum_{i=1}^{n}\left[\frac{\left(q_{e, \exp }-q_{e, \mathrm{cal}}\right)^{2}}{q_{e, \exp }}\right]_{i} \\
\Delta q_{e}=100 \sqrt{\frac{\sum\left|\left(q_{e, \exp }-q_{e, \mathrm{cal}}\right) / q_{e, \exp }\right|^{2}}{n-1}}
\end{gathered}
$$

where in two equations, $n$ is the observations in the experiments, $p$ is the number of parameters in the model, $q_{e \text {,exp }}$ is the observation of the batch experiment $i$, and $q_{e, \text { cal }}$ is estimated from the equation for the corresponding.

Table 2 Isotherm model parameters and error evaluation for adsorption of ciprofloxacin onto cerium oxide nanoparticles

\begin{tabular}{|c|c|c|c|c|c|c|}
\hline Model & $\boldsymbol{R}^{2}$ & \multicolumn{2}{|c|}{ Parameters } & HYBRID & $\boldsymbol{M P S D}$ & $\boldsymbol{\Delta} \boldsymbol{q}_{e}[\boldsymbol{\%}]$ \\
\hline Langmuir & 0.930 & $q_{m}=1.85 \mathrm{mg} / \mathrm{g}$ & $K_{L}=0.04 \mathrm{dm}^{3} / \mathrm{mg}$ & 768 & 38.72 & 37.68 \\
\hline Freundlich & 0.946 & $1 / n=0.14$ & $K_{F}=1.30$ & 785 & 40 & 38.98 \\
\hline
\end{tabular}

The isotherm model parameters with the various error functions used in the present study are given in Table 2. According to $R^{2}, M P S D, H Y B R I D$ and $\Delta q_{e}$ [\%], Freundlich isotherm model exhibited the best fit. Figure 6 presents the fitting curve of the Freundlich equation on the isotherm data. Therefore, the adsorption of CIP onto $\mathrm{CeO}_{2}-\mathrm{NP}_{\mathrm{S}}$ was a multilayer adsorption process, and the adsorption occurred at a heterogeneous surface [26]. Moreover, $1 / n$ values between 0 and 1 indicated a good adsorption [23]. 


\section{Adsorption thermodynamics}

Three basic parameters for thermodynamic study include standard enthalpy $\left(\Delta H^{\circ}\right)$, Gibbs free energy $\left(\Delta G^{\circ}\right)$ and standard entropy $\left(\Delta S^{\circ}\right)$, which can be evaluated by the following equations $[23,25]$ :

$$
K_{C}=\frac{q_{e}}{c_{e}}
$$

where $K_{c}$ is the equilibrium constant $\left[\mathrm{dm}^{3} / \mathrm{g}\right], q_{e}$ is the amount of adsorbed CIP on $\mathrm{CeO}_{2}$ $\mathrm{NP}$ at equilibrium $[\mathrm{mg} / \mathrm{g}]$, and $C_{e}$ is the equilibrium concentration of the CIP in the solution $\left[\mathrm{mg} / \mathrm{dm}^{3}\right]$.

$$
\Delta G^{\circ}=-\mathrm{R} T \cdot \ln K_{c}
$$

where $\mathrm{R}$ is the universal gas constant $(8.314[\mathrm{~J} / \mathrm{mol} \cdot \mathrm{K}])$, and $T$ is the temperature $[\mathrm{K}]$.

$$
\ln K_{\mathrm{c}}=\frac{\Delta S^{\circ}}{\mathrm{R}}-\frac{\Delta H^{\circ}}{\mathrm{R} T}
$$

The $\Delta H^{\circ}$ and $\Delta S^{\circ}$ values are derived from linear plot against $1 / T$, which are from the slope and intercept, respectively.

The adsorption kinetics of CIP onto $\mathrm{CeO}_{2}-\mathrm{NP}_{\mathrm{S}}$ were critically investigated at 298, 308 and $318 \mathrm{~K}$, respectively, and the thermodynamic parameters were calculated as shown in Table 3. All the values of $\Delta G^{\circ}$ was negative and it showed that the absorption process by $\mathrm{CeO}_{2}-\mathrm{NP}_{\mathrm{S}}$ was spontaneity. The decrease of $\Delta G^{\circ}$ happened with increase in temperature, indicating that the increasing temperature resulted in increase of spontaneity. The negative $\Delta H^{\circ}$ indicated the adsorption process were exothermic. According to Le Chatelier's principle, increasing the temperature reduced the reaction rate, and it was followed by reducing the maximum adsorption capacity. The positive $\Delta S^{\circ}$ showed the regularity at solid/solution interface decreased during absorption, and the reaction was irreversible [27].

Table 3

Thermodynamic parameters for the adsorption of ciprofloxacin onto cerium oxide nanoparticles

\begin{tabular}{|c|c|c|c|}
\hline $\boldsymbol{T}(\mathbf{K})$ & $\boldsymbol{\Delta} \boldsymbol{G}^{\circ}[\mathrm{kJ} / \mathbf{m o l}]$ & $\Delta \boldsymbol{S}^{\circ}[\mathrm{kJ} / \mathbf{m o l} \cdot \mathbf{K}]$ & $\boldsymbol{\Delta} \boldsymbol{H}^{\circ}[\mathrm{kJ} / \mathbf{m o l}]$ \\
\hline 298 & -1213.6 & 0.003 & -1212.6 \\
\hline 308 & -1036.5 & & \\
\hline 318 & -1021.4 & & \\
\hline
\end{tabular}

Experimental conditions: $\mathrm{CeO}_{2}$-NPs mass $0.2 \mathrm{~g}$, initial CIP concentration $200 \mathrm{mg} / \mathrm{dm}^{3}, \mathrm{pH} 5$

\section{Effect of pH}

The $\mathrm{pH}$ is an important parameter that influences on surface charges of absorbents, ionization degree of different pollutants and seperation of application groups on absorbent active sites. Effect of different $\mathrm{pH}$ (3-11) in adsorption of CIP on $\mathrm{CeO}_{2}-\mathrm{NPs}$ was shown in Figure 7. Upon increasing the $\mathrm{pH}$ from 3 to 5 , the removal efficiency of CIP significantly increased from 95 to $99 \%$. While $\mathrm{pH}$ was higher than 5, the removal efficiency was slightly reduced. The adsorption capacity showed the similar trend. The effect of $\mathrm{pH}$ on the adsorption of CIP depends on point of zero charge $\left(\mathrm{pH}_{\mathrm{pzc}}\right)$ and $\mathrm{p} K_{\mathrm{a}}$ parameters. The $\mathrm{p} K_{\mathrm{a}}$ for CIP was 5.7 and the $\mathrm{pH}_{\mathrm{pzc}}$ of $\mathrm{CeO}_{2}-\mathrm{NPs}$ was 7.8 [28, 29]. In acidic condition, both CIP and $\mathrm{CeO}_{2}-\mathrm{NPs}$ have positive changes, which hinders the contact between $\mathrm{CIP}$ and $\mathrm{CeO}_{2}-\mathrm{NPs}$ by charge repelling. 


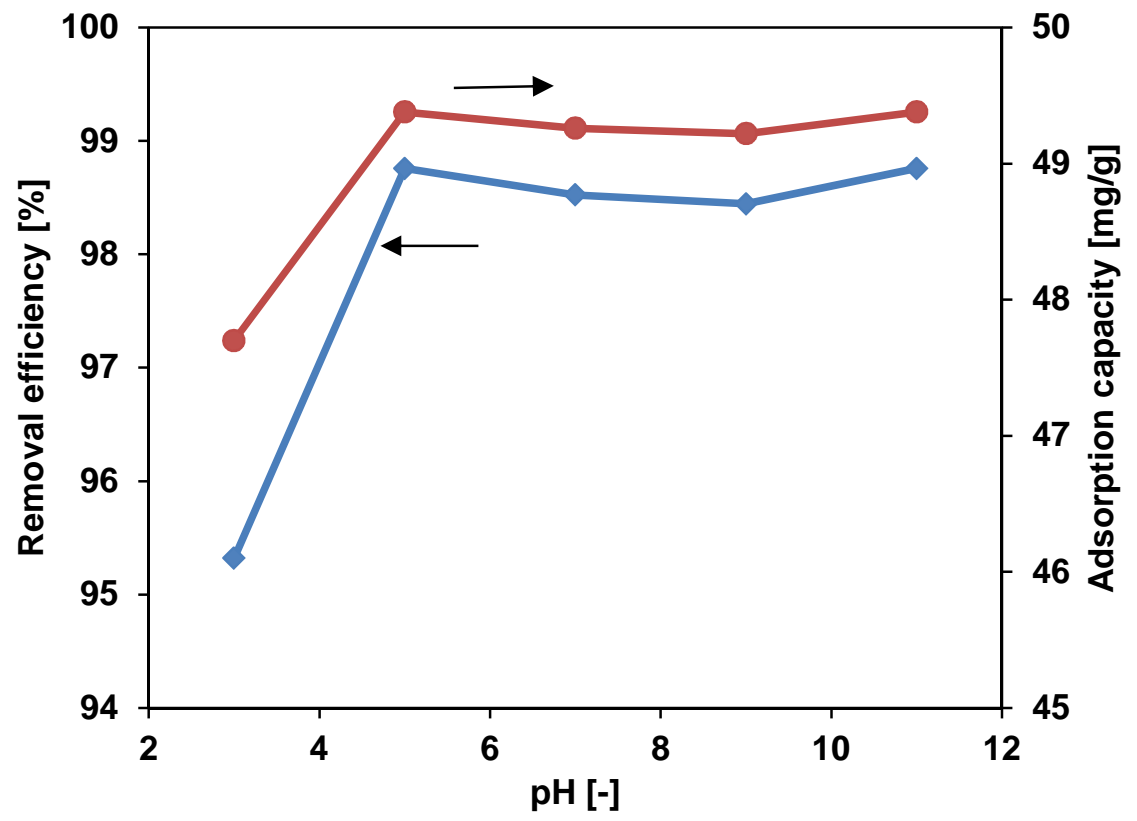

Fig. 7. Effect of $\mathrm{pH}$ on adsorption of ciprofloxacin onto cerium oxide nanoparticles. Experimental condition: $\mathrm{CeO}_{2}$-NPs dosage $0.2 \mathrm{~g} / \mathrm{dm}^{3}$, initial CIP concentration $50 \mathrm{mg} / \mathrm{dm}^{3}$, contact time $60 \mathrm{~min}$

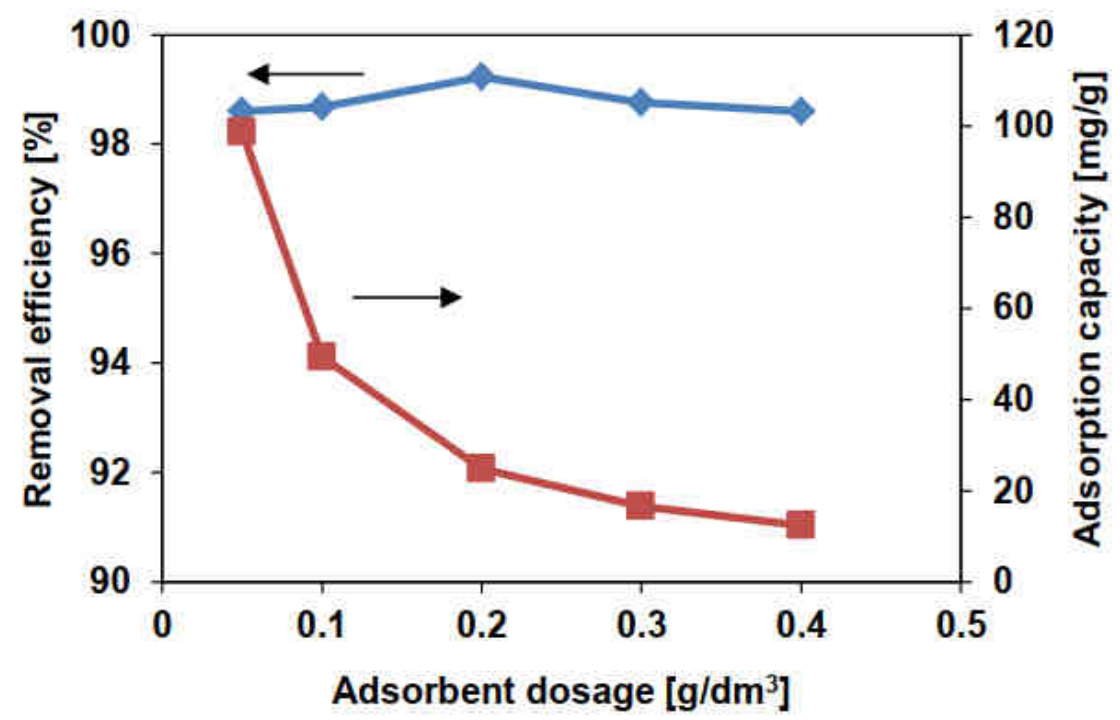

Fig. 8. Effect of adsorbent dosage on ciprofloxacin adsorption onto cerium oxide nanoparticles. Experimental condition: initial CIP concentration $50 \mathrm{mg} / \mathrm{dm}^{3}, \mathrm{pH}$ 5, contact time $45 \mathrm{~min}$, ambient temperature 


\section{Effect of adsorbent dosage}

The adsorbent dosage is an important parameter in determining the adsorbent capacity of CIP onto $\mathrm{CeO}_{2}$-NPs. To study the effect of adsorbent dosage in removing CIP, $0.05-1 \mathrm{~g} / \mathrm{dm}^{3} \mathrm{CeO}_{2}-\mathrm{NPs}$ were used to conduct the adsorption experiments at conditions of initial CIP concentration of $50 \mathrm{mg} / \mathrm{dm}^{3}, \mathrm{pH}=5$, contact time of $45 \mathrm{~min}$, and ambient temperature. According to the results shown in Figure 8, with increase of $\mathrm{CeO}_{2}-\mathrm{NPs}_{\text {dose }}$ from 0.05 to $0.4 \mathrm{~g} / \mathrm{dm}^{3}$, the removal efficiency of CIP first increased and reached the maximum value of $99.22 \%$ at the $\mathrm{CeO}_{2}$ - NPs dose of $0.2 \mathrm{~g} / \mathrm{dm}^{3}$ with an adsorption capacity of $24.8 \mathrm{mg} / \mathrm{g}$, and then gradually decreased. The increase of removal efficiency of CIP is related to the increased active surface of $\mathrm{CeO}_{2}-\mathrm{NPs}$ with the increase in adsorbent dosage [30]. However, continuously increasing the adsorbent dosage would induce the agglomeration of nanoparticles that shelters the available adsorption sites. The maximum absorption capacity was $98.62 \mathrm{mg} / \mathrm{g}$ with the minimum adsorbent dosage of $0.05 \mathrm{~g} / \mathrm{dm}^{3}$, and it gradually decreased with increasing the adsorbent dosage.

\section{Effects of contact time and initial ciprofloxacin concentration}

The effects of contact time and initial CIP concentration on removal efficiency of CIP was studied in experimental conditions of contact time 20-120 min, $\mathrm{pH}=6, \mathrm{CeO}_{2}-\mathrm{NPs}_{\text {dose }}$ $0.2 \mathrm{~g} / \mathrm{dm}^{3}$, and initial CIP concentration $50-200 \mathrm{mg} / \mathrm{dm}^{3}$, and the results are shown in Figure 9. It was found that increasing the contact time slightly increased the removal efficiency. The limited enhancement is because the fast adsorption process occurred in the first $20 \mathrm{~min}$, and after that the adsorption slowly approached to equilibrium. At a fixed contact time, increased the initial CIP concentration promote the removal efficiency. In fact, the increase of initial CIP concentrations provides an important driving force to overcome the mass transfer resistance of the CIP between the solid phases and the aqueous phases, so increasing initial concentrations would enhance the adsorption efficiency [31].

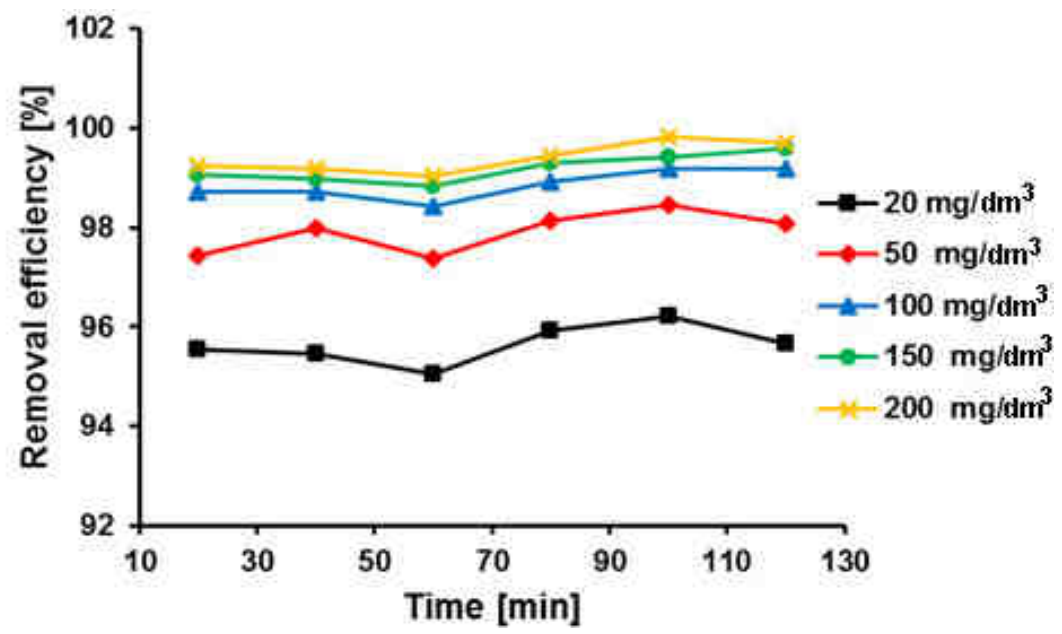

Fig. 9. Effects of contact time and initial ciprofloxacin concentration on removal efficiency of ciprofloxacin by cerium oxide nanoparticles. Experimental conditions: contact time 20-120 min, $\mathrm{pH} 6, \mathrm{CeO}_{2}$-NPs dose $0.2 \mathrm{~g} / \mathrm{dm}^{3}$, initial CIP concentration $50-200 \mathrm{mg} / \mathrm{dm}^{3}$ 


\section{Conclusions}

This study comprehensively investigated the adsorption of CIP onto $\mathrm{CeO}_{2}-\mathrm{NP}_{\mathrm{S}}$. For adsorption kinetics, both pseudo-first-order and pseudo-second-order models can well describe the experimental data, indicating that the adsorption process was controlled by both physical diffusion and chemical interaction. For adsorption isotherms, the Freundlich model could fit the experimental data better than the Langmuir and Temkin models, suggesting a multilayer adsorption process. The thermal dynamics study showed the absorption process was spontaneity, exothermic, and irreversible. In addition, the effects of various operating parameters were investigated, and the optimum conditions were determined as follows: initial CIP concentration $200 \mathrm{mg} / \mathrm{dm}^{3}, \mathrm{pH} 5, \mathrm{CeO}_{2}-\mathrm{NP}_{\mathrm{S}}$ dose $0.2 \mathrm{~g} / \mathrm{dm}^{3}$, and contact time $80 \mathrm{~min}$.

\section{Acknowledgements}

S. Rahdar and S. Ahmadi thank the Research Assistance of Zabol University of Medical Sciences (No.IR.ZBMU. REC.1398.014) for financial and spiritual.

Dr. Jie Fu thanks the financial support from the Power China Huadong Engineering Corporation (KY2016-02-04).

\section{References}

[1] Gao Y, Li Y, Zhang L, Huang H, Hu J, Shah SM, et al. J Colloid Interface Sci. 2012;368:540-546. DOI: 10.1016/j.jcis.2011.11.015.

[2] Agarwal S, Tyagi I, Gupta VK, Dehghani MH, Jaafari J, Balarak D, et al. J Mol Liq. 2016;224:618-623. DOI: 10.1016/j.molliq.2016.10.032.

[3] Wang Z, Shen D, Shen F, Wu C, Gu S. J Mol Liq. 2017;241:612-621. DOI: 10.1016/j.molliq.2017.05.097.

[4] Elmolla ES, Chaudhuri M. J Hazard Mater. 2010;173:445-449. DOI: 10.1016/j.jhazmat.2009.08.104.

[5] Gulkowska A, Leung HW, So MK, Taniyasu S, Yamashita N, Yeung LWY, et al. Water Res. 2008;42:395-403. DOI: 10.1016/j.watres.2007.07.031.

[6] Al-Musawi TJ. J Mol Liq. 2015;211:431-441. DOI: 10.1016/j.molliq.2015.06.067.

[7] Zhang Y, Jiao Z, Hu Y, Lv S, Fan H, Zeng Y, et al. Environ Sci Pollut Res. 2017;24:2987-2995. DOI: $10.1007 / \mathrm{s} 11356-016-7964-7$.

[8] Wu S, Zhao X, Li Y, Zhao C, Du Q, Sun J, et al. Chem Eng J. 2013;230:389-395. DOI: 10.1016/j.cej.2013.06.072.

[9] Carabineiro SA, Thavornamornsri T, Pereira MF, Figueiredo JL. Water Res. 2011;45:4583-4591. DOI: 10.1016/j.watres.2011.06.008.

[10] Rivera-Utrilla J, Sánchez-Polo M, Ferro-García MÁ, Prados-Joya G, Ocampo-Pérez R. Chemosphere. 2013;93:1268-1287. DOI: 10.1016/j.chemosphere.2013.07.059.

[11] Ay F, Kargi F. J Hazard Mater. 2010;179:622-627. DOI: 10.1016/j.jhazmat.2010.03.048.

[12] Yuan F, Hu C, Hu X, Qu J, Yang M. Water Res. 2009;43:1766-1774. DOI: 10.1016/j.watres.2009.01.008.

[13] Sirtori C, Zapata A, Oller I, Gernjak W, Agüera A, Malato S. Water Res. 2009;43:661-668. DOI: 10.1016/j.watres.2008.11.013.

[14] Vakili M, Rafatullah M, Salamatinia B, Abdullah AZ, Ibrahim MH, Tan KB, et al. Carbohydr Polym. 2014;113:115-130. DOI: 10.1016/j.carbpol.2014.07.007.

[15] Homem V, Alves A, Santos L. Chem Eng J. 2013;220:35-44. DOI: 10.1016/j.cej. 2013.01.047.

[16] Doltabadi M, Alidadi H, Davoudi M. Environ Prog Sustain. 2016;35:1078-1090. DOI: 10.1002/ep.12334.

[17] Shukla A, Zhang YH, Dubey P, Margrave JL, Shukla SS. J Hazard Mater. 2002;95:137-152. DOI: 10.1016/S0304-3894(02)00089-4.

[18] Peng X, Luan Z, Ding J, Di Z, Li Y, Tian B. 2005:1;59:399-403. DOI: 10.1016/j.matlet.2004.05.090.

[19] Phatai P, Futalan CM. Desalin Water Treat. 2015;57:1-10. DOI: 10.1080/19443994.2015.1027281.

[20] Su Y, Yang W, Sun W, Li Q, Shang JK. Chem Eng J. 2015;268:270-279. DOI: 10.1016/j.cej.2015.01.070.

[21] Liu W, Zhao X, Wang T, Fu J, Ni J. J Mater Chem A. 2015;3:17676-17684. DOI: 10.1039/C5TA04521E.

[22] Phokha S, Pinitsoontorn S, Maensiri S. Nano-Micro Lett. 2013;5:223-233. DOI: 10.1007/bf03353753. 
[23] Peng F, He PW, Luo Y, Lu X, Liang Y, Fu J. Clean - Soil Air Water. 2012;40:493-498. DOI: 10.1002/clen.201100469.

[24] Vučurović VM, Razmovski RN, Tekić MN. J Taiwan Inst Chem E. 2012;43:108-111. DOI: 10.1016/j.jtice.2011.06.008.

[25] Fu J, Song R, Mao WJ, Wang Q, An SQ, Zeng QF, et al. Environ Prog Sustain. 2011;30:558-566. DOI: 10.1002/ep.10506.

[26] Dehghani MH, Faraji M, Mohammadi A, Kamani H. Korean J Chem Eng. 2017;34:454-462. DOI: 10.1007/s11814-016-0274-4.

[27] Dursun AY. Biochem Eng J. 2006;28:187-195. DOI: 10.1016/j.bej.2005.11.003.

[28] Peng H, Pan B, Wu M, Liu Y, Zhang D, Xing B. J Hazard Mater. 2012;233-234:89-96. DOI: 10.1016/j.jhazmat.2012.06.058.

[29] Avisar D, Lester Y, Mamane H. J Hazard Mater. 2010;175:1068-1074. DOI: 10.1016/j.jhazmat.2009.10.122.

[30] Rahdar S, Rahdar A, Igwegbe CA, Moghaddam F, Ahmadi S. Desalin Wat Treat. 2019;141:386-393. DOI: 10.5004/dwt.2019.23473.

[31] Bazrafshan E, Rahdar S, Balarak D, Mostafapour F, Zazouli M. Iran J Health Sci. 2015;3:15-28. DOI: 10.1080/19443994.2014.895778. 